explanation for the development of malignancy in the immunosuppressive drug-treated patient is not clear. Patients with rheumatoid arthritis show an appreciable increase in chromosomal abnormalities during therapy with cyclophosphamide (Tolchin et al., 1974) and it is possible that mutant cells are not properly recognized and destroyed as a result of defects in the immunosurveillance mechanism (Burnet, 1967). The interpretation that the present patient developed a tumour related to his immunosuppressive therapy is conjectural but the fact remains that tumour development should be considered as a potential hazard of cyclophosphamide therapy.

\section{References}

BURNET, F.M. (1967) Immunological aspects of malignant disease. Lancet, i, 1171.

Cooperating Clinics Committee of American RheumaTism Association (1970) A controlled trial of cyclophosphamide in rheumatoid arthritis. New England Journal of Medicine, 283, 883.

Doll, R. \& Kinlen, L. (1970) Immunosurveillance and cancer: epidemiological evidence. British Medical Journal, 4, 420.

Tolchin, S.F., Winkelstein, A., Rodnan, G.P., Pan, S.F. \& Nankin, H.R. (1974) Chromosome abnormalities from cyclophosphamide therapy in rheumatoid arthritis and progressive systemic sclerosis (scleroderma). Arthritis and Rheumatism, 17, 375.

\title{
Histiocytic medullary reticulosis with hypogammaglobulinaemia and disseminated intravascular coagulation
}

\author{
P. D. Clarke \\ B.M., M.R.C.P., Surgeon Lt Commander, R.N.
C. W. EDWARDS
M.D., M.R.C.Path.

R. S. Amos

M.B., M.R.C.P.
A. M. GEDDES
M.B., F.R.C.P.

\section{Departments of Communicable and Tropical Diseases and Pathology, East Birmingham Hospital, Birmingham}

\begin{abstract}
Summary
A case of histiocytic medullary reticulosis in a 45year-old man is described. The presentation with a swinging pyrexia is typical. Associated features were very low levels of all immunoglobulins and proved disseminated intravascular coagulation. Heparin therapy was given and the difficulties of controlling such treatment are demonstrated. It is concluded that an increased awareness of the condition as a cause of pyrexia might lead to an improvement in prognosis.

\section{Introduction}

Histiocytic medullary reticulosis (HMR) is a rare disorder with a rapidly progressive course, characterized by wasting, fever and enlargement of liver and spleen. The essential anatomical change is a proliferation of atypical histiocytic cells, mainly in the spleen, liver, lymph nodes and bone marrow and was first reported by Scott and Robb Smith (1939).

Correspondence: Surgeon Lt/Cmdr P. D. Clarke, R.N., Department of Medicine (Sub-department of Communicable and Tropical Diseases), East Birmingham Hospital, Bordesley Green East, Birmingham B9 5ST.
\end{abstract}

\section{Case report}

A 45-year-old man was referred to the East Birmingham Hospital with rigors and severe sore throat of 1 week's duration. He had suffered from depression for 4 months and had been under treatment for the last month with tranylcypromine (parnate), a monoamine oxidase inhibitor. He was of good general physique, the skin showed patches of seborrhoeic eczema but no bruising or petechial haemorrhage. There were deep ulcers covered with a grey exudate on the fauces and the spleen was firm and just palpable. He had a swinging pyrexia of up to $40^{\circ} \mathrm{C}$.

The haemoglobin level fell from $12.3 \mathrm{~g} / \mathrm{dl}$ on admission to $7.9 \mathrm{~g} / \mathrm{dl}$ by the ninth day. There was evidence of extensive haemolysis with a four-fold rise in unconjugated bilirubin and an excess of urobilinogen in the urine. Liver enzymes were moderately elevated. An initial peripheral white blood count of $17 \times 10^{9} / 1$ with a differential of $87 \%$ polymorphs, $5 \%$ lymphocytes and $8 \%$ monocytes, rose slowly during the illness to reach $33 \times 10^{9} / 1$ on the seventh day but still with a marked lymphopenia 
TABLE 1. Clotting investigations

\begin{tabular}{lcccc}
\hline \multicolumn{1}{c}{ Day } & 3 & 5 & 7 & 9 \\
\hline Platelets $10^{9} / 1$ & 26 & 26 & 35 & 46 \\
Prothrombin time index (sec) & $21 / 13$ & $24 / 13$ & $32 / 13$ & $55 / 13$ \\
Partial thromboplastin time (sec) & $60 / 48$ & $70 / 38$ & $>6 \mathrm{~min}$ & $92 / 43$ \\
Thrombin time (sec) & $11 / 11$ & - & $>6 \mathrm{~min}$ & $11 / 11$ \\
Fibrin degradation products & $>10<40$ & - & - & - \\
\hline
\end{tabular}

of $5 \%$. Bone marrow examination showed no specific reactive change. Immature megakaryocytes were plentiful and there was a slight increase in reticulum and monocytoid cells.

The clotting investigations are shown in Table 1. No anti-B antibody was detected despite being blood group A. Serum immunoglobulins were IgG $3.7 \mathrm{~g} / 1$ (normal 16), IgA $0.5 \mathrm{~g} / \mathrm{l}(5.2)$, IgM $0.02(1.4)$. Lymphocyte transformation tests showed a very low response to PHA, and ' $T$ ' cell rosette formation was absent. ' $B$ ' cells, however, were normal.

On the third day after admission, intramuscular penicillin and pooled human immunoglobin were commenced and the pyrexia rapidly settled. On the fifth day, however, he became jaundiced. His temperature rose again and he developed profound hypotension. This was thought to be due to a Gramnegative septicaemia and he was treated with gentamicin. Intravenous heparin therapy was started in view of the disseminated intravascular coagulation (DIC) and 4000 i.u. 4 hourly by intravenous bolus injection was given. After $36 \mathrm{hr}$ of this treatment, he developed extensive bleeding and treatment was stopped. Prothrombin and thrombin times were greatly prolonged (Table 1 ) but the platelet count doubled during this time. His serum urea began to rise sharply with minimal urinary output and by the sixth day he was in established renal failure. Haemodialysis was started on the ninth day but he died within a few hours of its commencement.

At post-mortem, the spleen and liver were enlarged but lymph nodes were of normal size. There was haemorrhagic pulmonary oedema and extensive bleeding into gut. Histology revealed an infiltrate of abnormal histiocytic and phagocytic cells in lymph nodes, liver, spleen and bone marrow.

\section{Discussion}

Approximately 100 cases of histiocytic medullary reticulosis have been reported since the first description by Scott and Robb Smith (1939). The range of histiocytic malignancies is discussed by Cline and Gold (1973) and HMR is now emerging, from previously confused nomenclature, to establish itself as a clinical and pathological entity (Byrne and Rappaport, 1973). This clinical presentation with high fever and a rapidly fatal course is typical. Lymph nodes are usually enlarged and abnormal histiocytic cells may rarely be seen in the peripheral blood. Pancytopenia and haemolysis are common, Lynch and Alfrey (1965) attributing both to phagocytosis by malignant cells. Hypogammaglobulinaemia, which is not uncommon in other lymphoid neoplasms, has not previously been reported. No previous reports of DIC are known to us, although thrombocytopenia reported by Natelson (1968) is common. The difficulties and dangers inherent in the use and control of heparin therapy for this complication are well illustrated.

Diagnosis in life is difficult and is usually made at biopsy of liver, lymph nodes or bone marrow. Attempts at treatment are usually unsuccessful, only transient response having been obtained with corticosteroids and cytotoxic drugs (Byrne and Rappaport, 1973). Perhaps, however, increased awareness of the condition as a cause of pyrexia of unknown origin might lead to ante-mortem diagnosis and an improvement in prognosis.

\section{Acknowledgment}

I (P.D.C.) am grateful for the permission of the Medical Director General (Naval) to submit this article for publication.

\section{References}

BYRNE, G.E. \& RAPPAPORT, H. (1973) Malignant histiocytosis. GANN Monograph Cancer Research, No. 15, 145.

Cline, J.M. \& Gold, D.W. (1973) A review and reevaluation of the histiocytic disorders. American Journal of Medicine, $55,49$.

LyNCH, E.C. \& Alfrey, C.P. (1965) Histiocytic medullary reticulosis, hemolytic anaemia due to erythrophagocytosis by histiocytes. Annals of Internal Medicine, 63, 666.

NATElSON, E.A. (1968) Histiocytic medullary reticulosis. The role of phagocytosis in pancytopenia. Archives of Internal Medicine, 122, 223.

ScotT, R.B. \& Roвb Smith, A.H.T. (1939) Histiocytic medullary reticulosis. Lancet, ii, 194. 